DOI: $10.14451 / 2.130 .26$

\title{
НЕПРЕОДОЛИМАЯ СИЛА И НЕВОЗМОЖНОСТЬ
}

\author{
(c) 2019 Посохов Сергей Петрович \\ кандидат юридических наук, старший преподаватель кафедры гражданского права \\ и процесса и международного частного права юридического института \\ Российский университет дружбы народов, Россия, Москва \\ E-mail: Posohov_civil@mail.ru
}

Соотношение непреодолимой силы как обстоятельства, исключающего гражданско-правовую ответственность, с невозможностью исполнения обязательств и существенным измением обстоятельств.

В статье исследуется соотношение непреодолимой силы с невозможностью исполнения обязательств и существенным изменением обстоятельств, в результате которого делается различие между указанными институтами и определяются юридические последствия гражданско-правового договора на который оказывают влияние описанные выше обстоятельства.

Ключевые слова: ответственность, обстоятельства непреодолимой силы, невозможность исполнения, убытки, ущерб, существенное изменение обстоятельств, вина, причинно-следственная связь

Следует отметить, что институт непреодолимой силы на первый взгляд имеет много общего с невозможностью исполнения и существенным изменением обстоятельств. Так или иначе, указанные институты связаны с определенными юридическими последствиями, возникающими в сфере договорных обязательств.

По своей юридической природе существенно изменившиеся обстоятельства напоминают обстоятельства непреодолимой силы, тем не менее между указанными понятиями существует принципиальное различие.

По мнению В.А. Канашевского существует тонкая грань между положениями п. 3 ст. 401 и ст. 451 Гражданского кодекса РФ. Больше того, применение данных институтов в практическом плане порождает большие проблемы в части их разграничения между собой [1].

«Смешение названных правовых институтов вытекает не только из непонимания их правовой природы... но и из того, что могут возникнуть ситуации, которые одновременно являются непреодолимой силой и ведут к существенному изменению обстоятельств» [2].

Согласно п. 3 ст. 401 Гражданского кодекса РФ непреодолимая сила - это чрезвычайные и непредотвратимые обстоятельств [3]. В этой связи, следует отметить, что признаками непреодолимой силы является объективность, чрезвычайность, объективная непредотвратимость событий.

Основным имеющим существенное значе- ние критерием при определении обстоятельств непреодолимой силы являются понятия вины и безвиновной ответственности, что вытекает из п. 1 ст. 401 Гражданского кодекса РФ [4].Понятия вины и безвиновной ответственности в свою очередь говорят о том, что отношения, на которые оказывают влияние обстоятельства непреодолимой силы связаны с гражданско-правовой ответственностью, включая ответственность без вины в сфере предпринимательских отношений, тогда как положения ст. 451 Гражданского кодекса РФ об изменении и расторжении договора в связи с существенным изменением обстоятельств имеют несколько иную юридическую природу и акцент свой делают на совершенно ином. «Положения института существенного изменения обстоятельств связаны в первую очередь с вопросами динамики обязательственного правоотношения, а не с вопросами освобождения должника от ответственности» [5].

Применение норм, связанных с регулированием отношений в связи с возникшими обстоятельствами непреодолимой силы, освобождает должника от ответственности, что является следствием абсолютной невозможности исполнения обязательства. В свою очередь, существенное изменение обстоятельств не связано с невозможностью исполнения должником своих обязанностей, поскольку основное значение применения данных норм сводится к установлению баланса интересов сторон договора.

Институты существенного изменения обсто- 
ятельств и непреодолимой силы имеют и иные между собой различия.

Так, институт существенного изменения обстоятельства является не только специальным правовым средством, как отмечает Очхаев Т.Г., «направленным на стабилизацию нарушенной динамики обязательственного правоотношения и обеспечение стабильности договора, но и комплексным механизмом, в котором заложены вариации сценариев развития событий в случае существенного изменения обстоятельств» [6].

Следует отметить, что для расторжения договора в связи с существенно изменившимися обстоятельствами гражданский закон предписывает соблюдения досудебного порядка урегулирования спора. И лишь только в случае неудачных переговоров суд либо расторгает договор, либо вносит в него изменения в целях обеспечения справедливого распределения расходов и как следствие - восстановления баланса интересов сторон. Главной же целью института непреодолимой силы является освобождение от договорной обязанности должника.

Таким образом, категории существенного изменения обстоятельств и обстоятельств непреодолимой силы относятся к разным институтам гражданского права, преследующие различные юридические цели и устанавливающие различные правовые последствия.

Четкое понимание различий между институтом существенного изменения обстоятельств и невозможности исполнения очень важно на практике, поскольку от правильно примененной нормы права будет завесить достигнет ли результат. Ведь при существенно изменившихся обстоятельствах он один, а при невозможности исполнения совсем другой.

Как справедливо указывал Т.Г. Очхаев «нормы Гражданского кодекса РФ, касающиеся невозможности исполнения обязательств, обстоятельств непреодолимой силы и существенного изменения обстоятельств, являются на практике тем последним «бастионом», за которым пытаются укрыться стороны» [7].

Проведение анализа института существенного изменения обстоятельств в соотношении с институтом невозможности исполнения обязательства необходимо также и в связи с тем, что в отечественном правопорядке происходит смешение данных институтов и определение их как однопорядковых. Так, например то, что указанные категории идентичны неоднократно на это в своих работах ученые. Например, Кондратьева Е.М. утверждала, что существенное изменение обстоятельств это и есть невозможность исполнения обязательств, вызванная различными причинами юридического либо экономического характера [8].

Исследуя институт невозможности исполнения, стоит отметить, что данная категория права как ни одна другая имеет практически бесчисленную форму своего выражения. Так, например, невозможность исполнения может быть фактической, юридической, длительной временной, экономической, политической, моральной [9]. Выделяют также объективную, субъективную невозможность исполнения и даже логическую [10].

Юридическое понятие невозможности исполнения обязательств обусловлено нормативноправовыми критериями, являющиеся следствием деятельности органов государственной власти, а также органов местного самоуправления.

Физическая невозможность может быть связана с гибелью какой-либо вещи, преимущественно конечно же индивидуальноопределенной.

Объективная невозможность связана с неисполнением без вины должника и носит объективно-обусловленный характер, тогда как субъективная отражает именно данный фактор.

Следует отметить, что основное значение института существенного изменения обстоятельств связано с тем, чтобы создать условия, при которых заключенный договор не потерял ожидаемый социально-экономический эффект и чтобы стороны остались при наступлении таких обстоятельств в состоянии взаимной выгоды. Больше того, исходя из тех условий, с которыми гражданское законодательство связывает применение ст. 451 Гражданского кодекса РФ, можно прийти к выводу о том, что целью указанного института является восстановление баланса интересов сторон договора, который может быть нарушен при возникновении непредвиденных и непредотвратимых сторонами обстоятельств.

Что касается невозможности исполнения, то согласно ст. 416 Гражданского кодекса РФ обязательство прекращается невозможностью исполнения, если она вызвана наступившим после возникновения обязательства обстоятельством, за которое ни одна из сторон не отвечает. При таких обстоятельствах, обусловленных объективной невозможностью, например, в связи с 
гибелью вещи, изменить обязательство не представляется возможным.

Кроме того, для того чтобы возникли основания для применения ст. 451 Гражданского кодекса РФ необходимо соблюдение четырех основных условий, предусмотренных в п. 2 указанной статьи, в отношении возникшего обстоятельства, а именно:

- непредвиденность обстоятельств;

- непреодолимость обстоятельств;

- ни обычай, ни существо договора не предполагают необходимости возложения риска происшедшего изменения обстоятельств на заинтересованную сторону;

- исполнение договора без изменения его условий настолько нарушило бы соответствующее договору соотношение имущественных интересов сторон и повлекло бы для заинтересованной стороны такой ущерб, что она в значительной степени лишилась бы того, на что была вправе рассчитывать при заключении договора.

С точки зрения практической установление всех вышеназванных условий осложняется весьма кропотливым процессом их исследования юрисдикционным органом, что в условиях существующей нагрузки, а порой недостаточной квалификации судьи, делает решение вопроса в случае возникновения коллизии между статьями 451 и 416 Гражданского кодекса РФ приоритет в пользу статьи 416.
Следующее различие объясняется тем, что, если обязательство в соответствии со ст. 416 Гражданского кодекса РФ прекращается с момента возникновения невозможности исполнения, тогда как существенно изменившиеся обстоятельства, приводят к изменению либо расторжению договора. При этом, расторжение или изменение условий договора может быть обусловлено соглашением сторон либо в случае недостижения согласия между сторонами заключить соглашение добровольно - по решению суда.

С учетом сказанного, можно прийти к выводу о следующих различиях между институтами существенного изменения обстоятельств и невозможности исполнения.

Во-первых, цель института существенно изменившихся обстоятельств направлена на создание условий поддержания баланса между сторонами имущественных отношений, тогда как институт невозможности исполнения имеет целью прекращение гражданско-правовых обязательств;

Во-вторых, для применения института существенно изменившихся обстоятельств направлена требуется доказать одновременное наличие вышеназванных четырех условий, тогда как нормы о невозможности исполнения, обусловлены фактом наступления такого обстоятельства как невозможность.

\section{Библиографический список}

1. Канашевский В.А. Условия о форс-мажоре во внешнеэкономических контрактах // Журнал российского права. 2009. № 2

2. Дудко А.Г. Существенное изменение обстоятельств как основание изменения или расторжения договора // Вестник Московского университета. Сер. 11. Право. 2000. № 1. С. 103-104.

3. Гражданский кодекс Российской Федерации. Ч. 1. // СЗ РФ от 5 декабря 1994 г., № 32.

4. Брагинский М.И., Витрянский В.В. Договорное право: общие положения. Книга первая. 2-е изд. С. $752-753$.

5. Очхаев Т.Г. Изменение и расторжение договора в связи с существенным изменением обстоятельств. Статут, 2017 г. // СПС «Консультант Плюс».

6. Очхаев Т.Г. Указанное сочинение// СПС «Консультант Плюс».

7. Очхаев Т.Г. Указанное сочинение// СПС «Консультант Плюс».

8. Кондратьева Е.М. Концепции регулирования изменившихся обстоятельств во внешнеторговых сделках. Вестник Нижегородского университета им. Н.И. Лобачевского, 2014, № 5, с. 96-101

9. Bürgerliches Gesetzbuch Deutschland // www. Bürgerliches.

10. Ойгензихт В.А. Проблемы риска в гражданском праве. Душанбе: Ирфон, 1972. С. 168-177. 